\title{
Oil Price Forecasting Using Crack Spread Futures and Oil Exchange Traded Funds
}

\author{
Hankyeung Choi ${ }^{1}$, David J. Leatham², Kunlapath Sukcharoen ${ }^{2}$
}

ABSTRACT Given the emerging consensus from previous studies that crude oil and refined product (as well as
crack spread) prices are cointegrated, this study examines the link between the crude oil spot and
crack spread derivatives markets. Specifically, the usefulness of the two crack spread derivatives
products (namely, crack spread futures and the ETF crack spread) for modeling and forecasting dai-
ly OPEC crude oil spot prices is evaluated. Based on the results of a structural break test, the sample
is divided into pre-crisis, crisis, and post-crisis periods. We find a unidirectional relationship from the
two crack spread derivatives markets to the crude oil spot market during the post-crisis period. In
terms of forecasting performance, the forecasting models based on crack spread futures and the
ETF crack spread outperform the Random Walk Model (RWM), both in-sample and out-of-sample.
In addition, on average, the results suggest that information from the ETF crack spread market
contributes more to the forecasting models than information from the crack spread futures market.

KEY WORDS: oil price forecasting, crack spread futures, oil-related exchange traded funds, multivariate GARCH model

\section{JEL Classification: C18, C58, G17, Q47}

${ }^{1}$ Ministry of Strategy and Finance, Sejong Special Self-Governing City, Republic of Korea; ${ }^{2}$ Department of Agricultural Economics, Texas A\&M University, USA

\section{Introduction}

Crude oil is an important energy commodity that is vital for most economic activities. Consequently, numerous studies have been devoted to modeling and forecasting crude oil prices. In recent years, the link between the crude oil and refined product markets has been addressed often in the energy economics literature. In particular, several studies have examined the existence of a long-run equilibrium relationship between the prices of crude oil and refined products (Asche, Gjolberg, \& Völker, 2003; Gjolberg \& Johnsen,

Correspondence concerning this article should be addressed to: Kunlapath Sukcharoen, Department of Agricultural Economics, Texas A\&M University, College Station, TX 77843, USA, Phone: +1 (314) 359-8847. E-mail: kunlapath@tamu.edu
1999; Haigh \& Holt, 2002; Lanza, Manera, \& Giovannini, 2005; Serletis, 1994). The emerging consensus from these studies is that crude oil and refined product prices are cointegrated. As a result, we should be able to forecast future oil price movements based on information from the refined product markets. However, only a few empirical works have investigated the ability of refined product prices to forecast the price of crude oil (see, for example, Gjolberg \& Johnsen, 1999; Lanza et al., 2005; Murat \& Tokat, 2009). A deeper understanding of the relationship between the crude oil and refined product markets and of the predictive power of the refined products are indeed worthy of investigation and may carry important implications for energy consumers, producers, investors and policymakers. 
In this study, we explore the link between the crude oil spot and refined product derivatives markets and examine the ability of the refined product derivatives prices to predict movements in the crude oil price. In oil and energy markets, the profits of oil refiners, the major participants in the markets, depend largely on the crack spread (the difference between the price of crude oil and the prices of refined products - typically gasoline and heating oil). Because the demand from oil refiners, whose production decisions are tied directly to the crack spread, largely affect the price of crude oil (Verleger, 1982; Verleger, 2011), it is possible that there is a long-run equilibrium relationship between crude oil and crack spread derivatives prices. This study therefore examines the existence of long-run equilibrium price relationships between the crude oil and crack spread derivatives markets. Specifically, we explore the equilibrium price relationships between (i) the OPEC crude oil spot and crack spread futures and (ii) the OPEC crude oil spot and Exchange Traded Fund (ETF) crack spread. The Granger causality is then used to analyze the lead-lag relationship and determine whether the crack spread derivatives prices are useful for forecasting the movements of crude oil spot prices. Finally, we compare the forecasting ability of the two crack spread derivatives with that of a conventional Random Walk Model (RWM).

Our paper contributes to the existing literature by enriching the understanding of the dynamic relationships between crude oil spot and refined product derivatives prices in the following ways. First, unlike many previous studies, we focus on the prices of crude oil spot and crack spread derivatives. With the notable exception of Murat and Tokat (2009), our study is among the first to examine the link between the crude oil spot and crack spread derivatives markets and to investigate oil price forecasting models based on information from the crack spread derivatives markets. Unlike Murat and Tokat (2009), we analyze not only the futures market but also the ETF market. Thus, the findings from this study also have implications regarding which market contributes more to the forecasting models. In addition, while Murat and Tokat (2009) ignore the presence of heteroskedasticity in the residuals, we correct for the time-varying nature of the variance and covariance of commodity prices and returns by utilizing a Multivariate GARCH (MGARCH) model. Second, whereas most of the previous literature, including Murat and Tokat (2009), focuses on either Brent or West Texas Intermediate (WTI) crude oil prices, we investigate the dynamics of the new OPEC Reference Basket (ORB) price. The understanding of the OPEC crude oil price is important given the share of OPEC's crude oil production and exports. The U.S. Energy Information Administration (2014) reports, "OPEC member countries produce approximately 40 percent of the world's crude oil and exports approximately 60 percent of the total petroleum traded internationally." In particular, the study allows us to answer whether the crack spread price data from the U.S. derivative markets can significantly explain OPEC crude oil price movements. In summary, given the limited empirical investigations of the link between the OPEC crude oil spot and refined product derivatives markets, the results from this study should provide useful information for both oil refiners and energy investors regarding portfolio investment and risk management.

The remainder of this paper is organized as follows. Section 2 contains a brief discussion of the theoretical background on predicting oil price movements using crack spread derivatives. Section 3 describes the data. Section 4 presents the methodology used in forming the forecasting models. Section 5 discusses the empirical results, and finally, Section 6 concludes.

\section{Predicting oil price movements using crack spread derivatives}

The idea of forecasting oil price movements using information from the crack spread futures market is based on two different arguments. The first argument relies on the proposition that the price of crude oil largely depends on the demand from oil refiners (Verleger, 1982; Verleger, 2011). The rationale behind this proposition is that oil refiners are most concerned with the crack spread, and therefore, they cut their levels of production when the price of crude oil is too high compared with the prices of their refined products (i.e., when the crack spread is too low). A decrease in production of refined products will, in turn, lower the price of crude oil through the lower demand for input (Verleger, 2011). This relationship suggests that we should be able to forecast future oil price movements based on information from the crack spread markets. Assuming that the efficient market hypothesis holds, 


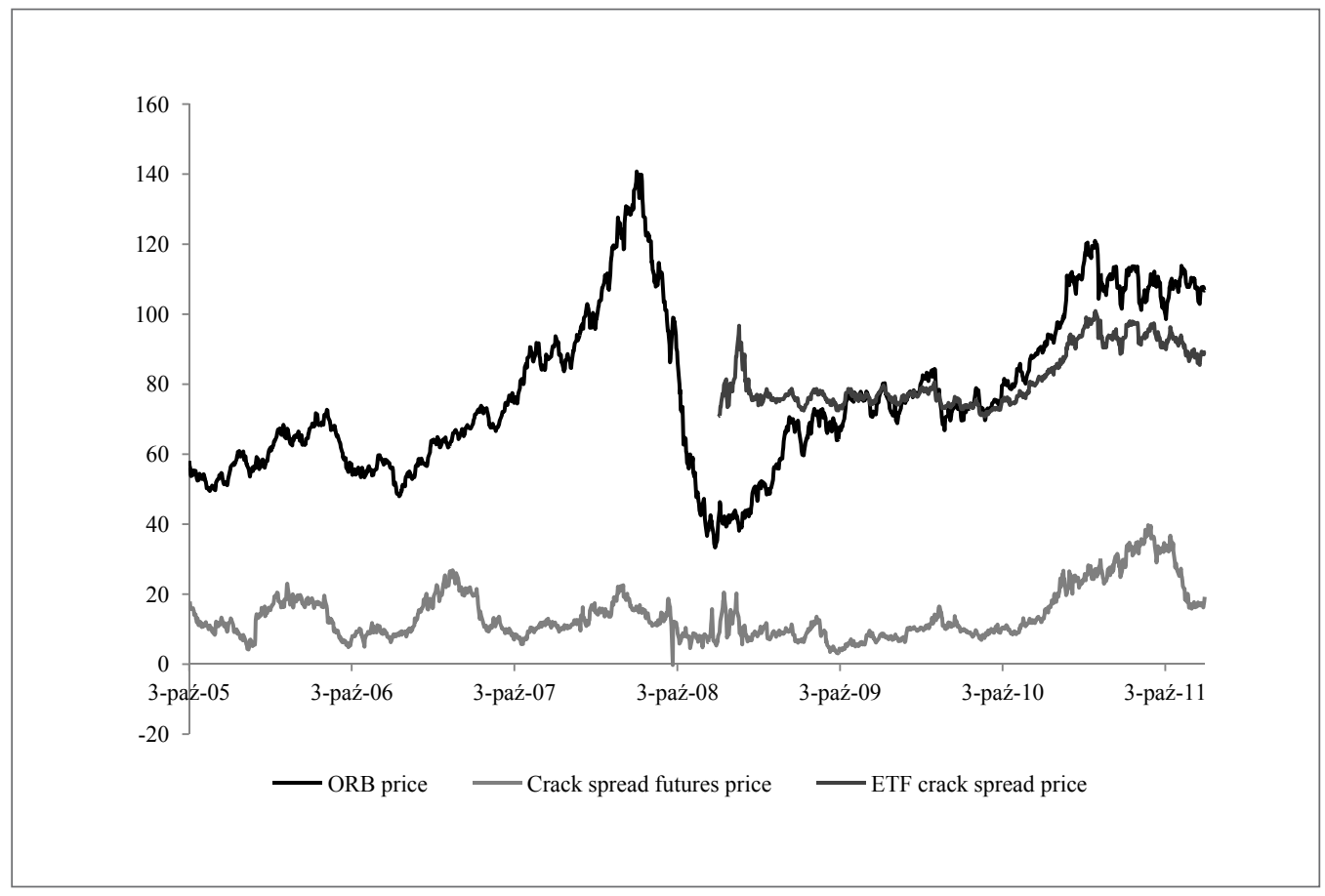

Figure 1. Daily ORB, crack spread futures, and ETF crack spread prices

then the prices of futures contracts based on crack spreads are the optimal forecasts of the crack spreads (e.g., Chinn \& Coibion, 2014; Lean, McAleer \& Wong, 2010; Ma, 1989). Accordingly, information contained in crack spread futures should at least partially explain future oil price movements.

The second argument relies on the proposition that there is a positive relationship between convenience yield (the benefit from physically holding a commodity rather than holding a futures contract for that commodity) and marginal production costs (Heinkel, Howe, \& Hughes, 1990). The reasoning behind this proposition is that, to maximize their profits, oil refiners respond to increased demand through immediate production when the marginal production costs are low and through the stock kept in inventory when the marginal costs of production are high. This strategy implies that when the marginal production costs are relatively inexpensive (expensive), the convenience yields are low (high). Because low marginal costs imply high profit margins or crack spreads, the proposition therefore suggests that there is a negative relationship between the convenience yields and crack spreads. This negative relationship is empirically verified by Edwards and Ma (1992) and Kocagil (2004). Given the Theory of Storage (Kaldor, 1939), commodity spot prices and commodity futures prices are related through the convenience yield. Thus, assuming the efficient market hypothesis, one should expect the existence of a long-run equilibrium relationship between crude oil spot and crack spread futures markets and that variations in crack spread futures can help explain crude oil price movements (see, for example, Asche et al., 2003; Gjolberg \& Johnsen, 1999; Haigh \& Holt, 2002; Lanza et al., 2005; Murat \& Tokat, 2009; Seletis, 1994).

Instead of relying solely on crack spread futures, the recent introduction of derivative-based ETFs allows oil refiners and investors to capture crack spread changes by purchasing equal units of the ProShares UltraShort DJ-UBS Crude Oil ETF (SCO), the United States Gasoline Fund (UGA) and the United States Heating Oil 
Fund (UHN) for the 2:1:1 crack spread (which refers to an approximation of the profit margin that oil refiners earn by turning two barrels of crude oil to one barrel of gasoline and one barrel of heating oil) because the price of the SCO fund represents the cost of purchasing two units of oil, where the values of the UGA and UHN funds are the proceeds derived from selling one unit of the respective distillate. Because these funds basically attempt to track the movements of the nearby futures, forwards, options and swap contracts, a positive relationship between crack spread futures and the ETF spread can be expected. Specifically, during the period from January 2009 to December 2011, the correlation coefficient between the daily prices of crack spread futures and the ETF crack spread is 0.9061 . Figure 1 clearly shows that the price of the ETF crack spread tracks the price of the crack spread futures fairly well (though they are not exactly the same). Given the positive relationship between the two crack spread derivatives, the ETF crack spread should also contain useful information about future oil price movements. Because the entry barrier in the ETF market is not as strict as in the futures markets, more diverse types of investors (i.e., not only oil refiners and institutional investors) can enter the ETF market, which raises the question of whether the ETF crack spread is better at explaining spot oil price movements than the crack spread futures. Given the recent increased investor interest in oil and refined product ETFs and the convenient trading system, we expect that the ETF market should contribute more to the forecasting models. To the best of our knowledge, no empirical research has yet directly addressed the role of the ETF crack spread in predicting the movements of the crude oil spot price. Therefore, this paper examines the forecasting power of both crack spread futures and crack spread ETFs for the first time.

\section{Data}

The analysis uses daily closing spot price data for the OPEC Reference Basket (ORB), daily closing futures price data for the front-month crude oil, RBOB regular gasoline, and No. 2 heating oil futures contracts, and daily closing ETF price data for the ProShares UltraShort DJ-UBS Crude Oil ETF (SCO), the United States Gasoline Fund (UGA) and the United States Heating Oil Fund (UHN). Given that the new ORB price was introduced on June 16, 2005, the data for spot and futures prices used in this study cover the period from October 3, 2005 to December 30, 2011. The data for the oil ETFs span the period from January 2, 2009 to December 30, 2011. Data from earlier periods were not used because trading did not begin on the SCO until November 25, 2008. The spot price, futures price and ETF price data are obtained from OPEC, New York Mercantile Exchange (NYMEX), and New York Stock Exchange (NYSE) data mines, respectively.

The closing prices for the three series are available at different times of the day. The closing spot price on a particular calendar date is obtained at 4:00 AM (EST) on the next calendar date. For instance, the Monday closing spot price is available in the early morning on Tuesday. On each trading day, the NYMEX futures closing prices are determined at 2:30 PM (EST), whereas the NYSE ETF closing prices are determined at 4:00 PM (EST). Given the discrepancies in real time, caution must be exercised in modeling and interpreting market relationships on the same calendar date. In particular, on a given calendar date, the futures price and the ETF price data are available before the OPEC crude oil price data. Thus, it would be inappropriate to allow the daily closing ORB price to influence the futures and ETF prices on the same calendar date. This disparity suggests that the model describing the relationship between the crude oil spot and crack spread derivatives should be recursive in nature.

The most common ratio of the crack spread for light oil is 3:2:1 (three crude oil, two gasoline, and one heating oil). However, OPEC crude oil is considered a representative of heavier oil compared with lighter oil such as WTI and Brent. Consequently, the 2:1:1 crack spread is a better description for the case of ORB prices because heavier crude oil usually yields less gasoline than the lighter oil such as WTI. Given that crude oil is quoted in dollars per barrel and refined products are quoted in cents per gallon, gasoline and heating oil prices are converted to dollars per barrel by multiplying the cents-per-gallon price by 42 . Accordingly, the 2:1:1 crack spread futures are calculated as

crack spread futures $=\left(\frac{1}{2} \times 42 \times R B\right)+\left(\frac{1}{2} \times 42 \times H O\right)-C L(1)$

where $R B, H O$, and $C L$ refer to gasoline futures price per gallon, heating oil futures price per gallon, and 
crude oil futures price per barrel, respectively. Finally, the 2:1:1 ETF crack spread can be calculated as

$$
\text { ETF spread }=S C O+U G A+U H N
$$

where $S C O, U G A$, and $U H N$ are the prices of the ProShares UltraShort DJ-UBS Crude Oil ETF (SCO), the United States Gasoline Fund (UGA) and the United States Heating Oil Fund (UHN), respectively.

\section{Methodology}

The aim of the analysis is to examine the contribution of two different derivatives products, crack spread futures and the derivative-based ETF crack spread, in explaining and forecasting crude oil price movements. Because the sample period includes the financial crisis in 2008, we first test for structural breaks in the data. We adopt a Zivot and Andrews (1992) test (hereafter a ZA test) to determine the breakpoint endogenously from the data. The ZA test is a simple modification of an Augmented Dickey-Fuller (ADF) test for unit root in which a dummy variable for a mean shift and/or a dummy variable for a trend shift occurring at each possible break date are added to the ADF test equation. In this study, we use the following ZA model that allows for both a mean shift and a trend shift at each possible break date $\left(T_{b}\right)$ :

$\Delta y_{t}=\mu+\alpha y_{t-1}+\beta t+\gamma D U_{t}\left(T_{b}\right)+\theta D T_{t}\left(T_{b}\right)+\sum_{j=1}^{k} \delta_{j} \Delta y_{t-j}+\varepsilon_{t}$

where

$D U_{t}, D T_{t}=\left\{\begin{array}{lc}1 & \text { if } t>T_{b} \\ 0 & \text { otherwise }\end{array}\right.$

The test assumes no structural break(s) under the null hypothesis of unit root (i.e., $\alpha=0$ ). The model is estimated for every possible break date. The candidate break date is then chosen where the one-sided t-statistic of $\alpha=0$ (against the alternative hypothesis that $\alpha<0$ ) in equation (3) is at a minimum (most negative). If the null hypothesis of no break(s) on the selected candidate break date is rejected, we conclude that there is a structural break on that particular candidate break date. After identifying the first breakpoint, the test is reapplied to each subsample until the test fails to detect evidence of an additional break. If structural breaks over the sample period exist, the analysis is also conducted for each sub-sample period to examine possible changes in the relationship between the variables of interest.

Similar to Murat and Tokat (2009), we explore the long-run equilibrium relationships between the crude oil spot and each crack spread derivative using the Error Correction Model (ECM). Given the timing consideration discussed above, the ECM framework is appropriate because the model is specified such that the current daily return in a particular market depends on its own past returns and past returns of the other market. Let $s_{t}$ denote the log of the crude oil price at time $\mathrm{t}$ and $c s_{t}$ denote the log of the crude oil futures price at time t. According to the Engle and Granger (1987) representation theorem, if both $s_{t}$ and $c s_{t}$ are integrated of order one, I(1), but the stochastic error terms are stationary (integrated of order zero, $\mathrm{I}(0)$ ), the two variables are said to be cointegrated. Cointegration between the two variables could then be established through the error correction representation as

$\Delta s_{t}=\alpha_{s}+\sum_{l=1}^{n} \alpha_{11}(l) \Delta s_{t-l}+\sum_{l=1}^{n} \alpha_{12}(l) \Delta c s_{t-l}+\tau_{s} E C T_{t-1}+\varepsilon_{s, t}$

$\Delta c s_{t}=\alpha_{c s}+\sum_{l=1}^{n} \alpha_{21}(l) \Delta s_{t-l}+\sum_{l=1}^{n} \alpha_{22}(l) \Delta c s_{t-l}+\tau_{c s} E C T_{t-1}+\varepsilon_{c s, t}$

where $\varepsilon_{t}$ is the stationary error term, and $E C T_{t-1}$ is the error correction term. $\tau_{s}$ and $\tau_{c s}$ are the adjustment coefficients. The ECM for the OPEC crude oil spot and the ETF crack spread follows a similar representation as equations (4) and (5) but with ETF in place of $c s$. We also conduct Granger causality tests to examine the lead-lag between markets and to determine whether the crack spread derivatives prices are useful for forecasting the movements of crude oil spot prices.

In the forecasting exercise, we also use the MGARCH model, which was introduced by Bollerslev, Engle, and Wooldridge (1998), to account for the presence of heteroskedasticity in the residuals of the estimated ECM. In this study, the constant conditional correlation (CCC) MGARCH model and the dynamic conditional correlation (DCC) MGARCH model are employed. Under the same bivariate error correction model (equations (4) and (5)), following Kroner and Sultan (1993), the conditional variance of the CCC MGARCH model can be specified as

$\varepsilon_{t}=\left[\begin{array}{ll}\varepsilon_{s, t} & \varepsilon_{c s, t}\end{array}\right]^{T} \mid I_{t-1} \sim N\left(0, H_{t}\right)$ 
where $\varepsilon_{s, t}$ and $\varepsilon_{c s, t}$ are error terms following the GARCH $(1,1)$ model with a zero mean and a conditional covariance matrix $H_{t}$ with a constant correlation $\rho$.

$H_{t}=\left[\begin{array}{cc}h_{s, t}^{2} & h_{s c s, t} \\ h_{s c s, t} & h_{c s, t}^{2}\end{array}\right]=\left[\begin{array}{cc}h_{s, t} & 0 \\ 0 & h_{c s, t}\end{array}\right]\left[\begin{array}{cc}1 & \rho \\ \rho & 1\end{array}\right]\left[\begin{array}{cc}h_{s, t} & 0 \\ 0 & h_{c s, t}\end{array}\right]=D_{t} R_{t} D_{t}$

$h_{s, t}^{2}=\beta_{0 s}+\beta_{1 s} \varepsilon_{s, t-1}^{2}+\beta_{2 s} h_{s, t-1}^{2}$

$h_{c s, t}^{2}=\beta_{0 c s}+\beta_{1 c s} \varepsilon_{c s, t-1}^{2}+\beta_{2 c s} h_{c s, t-1}^{2}$

where $h_{s, t}^{2}$ and $h_{c s, t}^{2}$ are the conditional variances for the crude oil spot and crack spread futures returns, respectively. The $\varepsilon_{t}$ is a standardized residual vector with a mean zero and a variance of one, which, in this study, is a $2 \times 1$ vector of normal, independent, and identically distributed (iid) innovation.

Because the assumption of constant correlation may be too restrictive, we also employ the DCC MGARCH model. In contrast to the CCC MGARCH model, the DCC MGARCH model, proposed by Engle (2002), allows a time-varying correlation $\rho_{t}$ :

$H_{t}=\left[\begin{array}{cc}h_{s, t}^{2} & h_{s c s, t} \\ h_{s c s, t} & h_{c s, t}^{2}\end{array}\right]=\left[\begin{array}{cc}h_{s, t} & 0 \\ 0 & h_{c s, t}\end{array}\right]\left[\begin{array}{cc}1 & \rho_{t} \\ \rho_{t} & 1\end{array}\right]\left[\begin{array}{cc}h_{s, t} & 0 \\ 0 & h_{c s, t}\end{array}\right]$

$\rho_{t}=\left(1-\lambda_{1}-\lambda_{2}\right) \rho+\lambda_{1} \rho_{t-1}+\lambda_{2} \varepsilon_{s, t-1} \varepsilon_{c s, t-1}$

where $\varepsilon_{t}$ is the standardized disturbance vector, $\rho$ is the unconditional correlation of the standardized residual $\left(\varepsilon_{t}\right)$, and $\lambda_{1}$ and $\lambda_{2}$ are parameters that capture the dynamics of a conditional quasi-correlation. $\lambda_{1}$ and $\lambda_{2}$ are nonnegative and satisfy $0 \leq \lambda_{1}+\lambda_{2}<1$. The MGARCH model for the OPEC crude oil spot and the ETF crack spread follows a similar representation as equations (6) to (10) but with ETF in place of $c s$.

Finally, we construct forecasts using a recursive window scheme. One-step-ahead forecasts of crude oil prices are generated dynamically from the insample parameter estimates. The forecasting performance of the two crack spread derivatives is then evaluated. A benchmark for evaluating different forecasting models is the random walk model (RWM) without drift. The accuracy of the forecasts obtained from the error correction models is assessed on the basis of the mean-absolute error (MAE) and the root mean-squared error (RMSE):

$\operatorname{MAE}(I)=\sum_{t=1}^{n}\left|\hat{y}_{t}-y_{t}\right| / n$

$\operatorname{RMSE}(I)=\sqrt{\sum_{t=1}^{n}\left(\hat{y}_{t}-y_{t}\right)^{2} / n}$

where $\hat{y}_{t}$ is the one-step-ahead forecast of the dependent variable for $\mathrm{t}=1, \ldots, \mathrm{n}$, and $y_{t}$ is the actual value. For the MGARCH models, the forecasting performance is evaluated by the following modified MAE and RMSE:

$\operatorname{MAE}(I I)=\sum_{t=1}^{n}\left|\frac{\hat{y}_{t}-y_{t}}{\sqrt{\text { variance }_{t}}}\right| / n$

$\operatorname{RMSE}(I I)=\sqrt{\sum_{t=1}^{n}\left(\frac{\hat{y}_{t}-y_{t}}{\sqrt{\text { variance }_{t}}}\right)^{2} / n}$

where variance, is a time-varying conditional variance in the MGARCH model. This method is used for scaling the residuals, which can be thought of as an element of variation that is not explained by the fitted model. The intuition behind this modification is that the MGARCH model could reduce the unexplained variance (or residual) in the ECM; thus, this benefit should also be taken into account. In addition, the Diebold-Mariano (Diebold \& Mariano, 1995) test is also conducted to assess whether the differences between the two rival forecasts are statistically significant.

\section{Empirical results}

Descriptive statistics are presented in Table 1. The presence of skewness, leptokurtosis, and non-normality (implied by the significant Jarque-Bera statistics) in all of the series suggest that the unconditional distributions of the crude oil spot, crack spread futures, and ETF crack spread prices and returns are asymmetric, fat tailed-tailed, and non-normal. Plots of the entire data series for the daily prices and daily log returns are presented in Figures 1 and 2, respectively. As shown in the figures, there are considerable co-movements among the prices and returns. However, the crack 


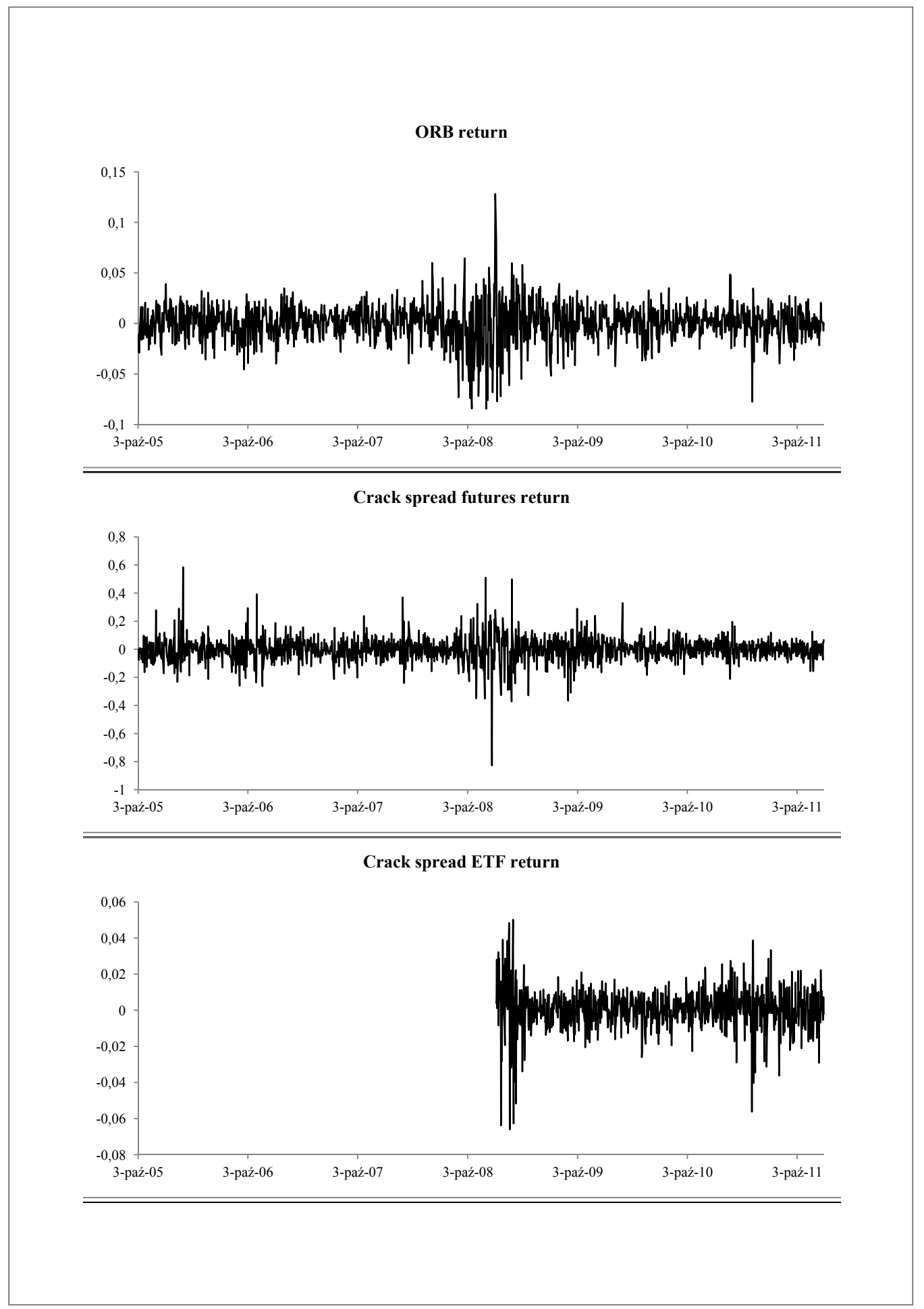

Figure 2. Daily log returns of ORB, crack spread futures, and ETF crack spread 
Table 1. Descriptive statistics

\begin{tabular}{|c|c|c|c|c|c|c|}
\hline \multirow[b]{2}{*}{ Statistic } & \multicolumn{3}{|c|}{ Log price } & \multicolumn{3}{|c|}{ First difference of log price (return) } \\
\hline & $\begin{array}{c}\text { Crude oil } \\
\text { spot }\end{array}$ & $\begin{array}{c}\text { Crack spread } \\
\text { futures }\end{array}$ & $\begin{array}{c}\text { ETF crack } \\
\text { spread }\end{array}$ & $\begin{array}{c}\text { Crude oil } \\
\text { spot }\end{array}$ & $\begin{array}{c}\text { Crack spread } \\
\text { futures }\end{array}$ & $\begin{array}{c}\text { ETF crack } \\
\text { spread }\end{array}$ \\
\hline Mean & 4.3077 & 2.5145 & 4.3974 & 0.0004 & 0.0001 & 0.0003 \\
\hline Median & 4.2856 & 2.4348 & 4.3502 & 0.0013 & 0.0024 & 0.0005 \\
\hline Std. Dev. & 0.2892 & 0.4820 & 0.0976 & 0.0178 & 0.0862 & 0.0119 \\
\hline Skewness & -0.0163 & 0.2501 & 0.6531 & -0.3442 & -0.2550 & -0.7277 \\
\hline Kurtosis & 2.3900 & 2.6487 & 1.9142 & 4.1110 & 9.8810 & 5.1606 \\
\hline JB test & 10.3553 & 10.3677 & 80.0621 & 47.4000 & 1321.1280 & 187.5280 \\
\hline (p-value) & $(0.0000)$ & $(0.0000)$ & $(0.0000)$ & $(0.0000)$ & $(0.0000)$ & $(0.0000)$ \\
\hline
\end{tabular}

Note: The JB (Jarque-Bera) test is a test of whether the series are derived from a normal distribution. The p-value of zero indicates that the null hypothesis "the distribution is normal" is rejected.

Table 2. Unit root tests

\begin{tabular}{lccc}
\hline & Variable $(\mathbf{X})$ and its first difference $(\Delta \mathbf{X})$ & ADF & KPSS \\
\hline $\log$ (crude oil spot) & $X$ & -1.7570 & $2.6400^{* *}$ \\
& $\Delta X$ & $-25.2330^{* *}$ & 0.1030 \\
$\log$ (crack spread futures) & $X$ & $-3.6630^{*}$ & $4.8000^{* *}$ \\
$\log ($ ETF crack spread) & $\Delta X$ & $-28.3740^{* *}$ & 0.0370 \\
& $X$ & -2.2140 & $3.5100^{* *}$ \\
\hline
\end{tabular}

Note: The null hypothesis of the ADF tests is the non-stationarity of the series considered, while the null hypothesis of the KPSS tests is the stationarity of the series considered. * and ** imply rejection of the null hypothesis at the $5 \%$ and $1 \%$ levels, respectively.

Table 3. Johansen Test for Cointegration

\begin{tabular}{lccc}
\hline & Maximum rank & Trace statistic & $\mathbf{5 \%}$ critical value \\
\hline crude oil spot and crack spread futures & 0 & 19.7725 & 15.4100 \\
& 1 & 2.1320 & 3.7600 \\
\hline crude oil spot and ETF crack spread & 0 & 25.8011 & 15.4100 \\
& 1 & 1.9651 & 3.7600 \\
\hline
\end{tabular}

Note: The null hypothesis of the Johansen test is that there is no lesser cointegration equation than the maximum rank level. The cointegrating vector of oil spot and crack spread is $\log (\mathrm{s})-1.073 \log (\mathrm{cs})-1.615=0$, and the cointegrating vector of oil and ETF is $\log$ (oil) -1.756 (ETF) $+3.225=0$. 
Table 4. Wald Test-Granger Causality

\begin{tabular}{|c|c|c|c|c|}
\hline Null hypothesis & Whole sample & Period 1 & Period 2 & Period 3 \\
\hline$\Delta s$ does not Granger cause $\Delta c s$ & $4.4691^{*}$ & $6.8845^{* *}$ & $5.5237^{*}$ & 2.5905 \\
\hline$\Delta \mathrm{cs}$ does not Granger cause $\Delta s$ & 0.8674 & 1.7873 & 0.7612 & $8.6193^{* *}$ \\
\hline$\Delta$ s does not Granger cause $\Delta$ ETF & & & & 0.0303 \\
\hline$\Delta$ ETF does not Granger cause $\Delta s$ & & & & $178.91^{* *}$ \\
\hline
\end{tabular}

Note: The table reports Wald test statistics. ${ }^{*}$ and ${ }^{* *}$ denote rejection of the null hypothesis at the $5 \%$ and $1 \%$ levels, respectively.

spread futures prices and returns appear to be relatively more volatile than the ORB and ETF crack spread prices and returns over the period analyzed.

The unit root behavior of the log price and log returns series is then investigated using the Augmented Dickey-Fuller (ADF) and the Kwiatknowski-PhillipsSchmidt-Shin (KPSS) tests. Table 2 shows the unit root test results. The ADF tests show that all of the log prices except the log price of crack spread futures have a unit root, but first-differencing leads to stationarity. Given the observed dynamics of the price and return data, the ADF regressions are run with a trend and a constant for the log price series and with a constant for the return series. The KPSS tests suggest that the log price series are non-stationary, whereas the return series are stationary. In summary, although there is a dispute regarding the stationarity of the crack spread futures, the logarithms of the crude oil and ETF crack spread prices are integrated of order one, I(1). We therefore employ the Johansen's cointegration technique (Johansen, 1988; Johansen, 1991) to test whether the crude oil spot price and its possible predictors (the prices of crack spread futures and the ETF crack spread) are cointegrated. The results are shown in Table 3. The lag length selection is based on the Akaike Information Criterion (AIC), Schwarz Bayesian Information Criterion (SIC) and Hannan-Quinn Information Criterion (HQC). For each pair, the null hypothesis of no cointegrated relationship is rejected, whereas the null hypothesis of having at most one cointegrated relationship cannot be rejected. This result implies that one cointegrating vector exists for each pair; thus, the longrun relationship should be considered when modeling the return dynamics. Therefore, an error correction model (ECM) would be appropriate to model and forecast the dynamic of crude oil prices.

\subsection{Structural breaks and causality test}

From the results of the ZA test, we identify two structural breaks: one on September 2, 2008 and the other on April 29, 2009. Those dates are consistent with the period of the 2008 financial crisis. In September 2008, Lehman Brothers submitted a bankruptcy petition, and Merrill Lynch was sold to the Bank of America. Additionally, during that month, the global stock markets, including the Dow Jones Industrial Average, the FTSE of England, the CAC40 of France, the Dax30 of Germany, and the Hang Seng of Hong Kong, dropped precipitously. Likewise, the price of oil decreased significantly to 30.28 dollars per barrel, its lowest level since the beginning of the 2008 financial crisis. After April 2009, the global oil market recovered from the price collapse resulting from the financial crisis. Because no further structural breaks are detected, the entire sample period was divided into three sub-periods: sub-period 1 (October 2005 to September 2008), sub-period 2 (October 2008 to April 2009), and sub-period 3 (May 2009 to December 2011). These divisions are denoted as the pre-crisis, crisis, and post-crisis periods.

Based on the detected structural breaks, we conduct a Granger-causality/ block exogeneity Wald test for the OPEC crude oil spot market and the crack spread futures market on the entire sample period and the three sub-sample periods. Because the ETF crack spread data could only be obtained beginning in January 
2009, the causality test between the oil spot and ETF crack spread markets is only applied for the post-crisis period. Table 4 reports the Wald test statistics. For the whole sample, we find that the crack spread futures market has no significant impact on the crude oil market, but an impact of the oil spot market on the crack spread futures market is observed. Similar results are obtained for the pre-crisis and crisis periods. For the post-crisis period, however, the dynamic between the two markets is reversed; instead, a unidirectional relationship from the crack spread futures market to the crude oil spot market is detected. This result is consistent with that of Murat and Tokat (2009), who study the relationship between WTI crude oil and the 3:2:1 crack spread futures markets. For the relationship between crude oil spot prices and ETF crack spread prices, the block exogeneity test indicates a strong unidirectional relationship from the ETF crack spread market to the OPEC crude oil market. In summary, in the post-crisis period, the price changes in the crack spread futures and ETF crack spread markets led to future OPEC crude oil spot price changes. This result implies that, for the post-crisis period, the crack spread futures and the ETF crack spread are useful for forecasting the movements of the OPEC crude oil spot prices.

\subsection{Estimation of the ECM and MGARCH models}

The estimation results from the four alternative error correction models are provided in Table 5. The first three models correspond to the relationship between the crude oil spot and crack spread futures markets during (i) the entire sample period, (ii) the pre-crisis and crisis periods (given the Granger-causality results, these two periods are combined), and (iii) the post-crisis period. The last model corresponds to the relationship between the crude oil spot and ETF crack spread markets during the post-crisis period. The estimated coefficients on the error correction terms (i.e., $E C T_{t-1}$ ) of the crack spread futures and ETF crack spread returns are all significant. This result confirms that all of the markets adjust to their long-run equilibrium. The lagged returns of the crack spread futures and ETF crack spread are significant only in the post-crisis period. This result implies that, after the crisis, the current OPEC crude oil return did respond to the returns of those variables in the previous period. The estimation results are consistent with the Granger-causality test results discussed in the previous section and hence confirm that the information provided by the two crack spread derivatives are useful in explaining OPEC crude oil price movements.

To compare and discuss the forecasting performance of the crack spread futures and ETF crack spread, we only focus on the post-crisis data. Taking into account the possibility of heteroskedasticity in the residuals of the estimated error correction models, the Breusch-Pagan (BP) and White tests are used to test for the presence of heteroskedastic disturbances. The results of both tests confirm that the null hypothesis of homoscedasticity is rejected at the $5 \%$ significance level for all residuals from the estimated error correction models. Therefore, the multivariate GARCH-type models are applied to account for the time-varying variance characteristic in the data.

The estimation results from the CCC and DCC MGARCH models are provided in Table 6. The sum of the coefficients of $\operatorname{arch}(1)$ and $\operatorname{garch}(1)$ are close to 1 , implying that shocks cause a high persistence in the volatility. For both the ECM-MGARCH 1 (CCC and DCC models for oil spot and crack spread futures) and ECM-MGARCH 2 (CCC and DCC models for oil spot and ETF crack spread), the sum in the crack spread equation is higher than in the crude oil spot equation. This result suggests that the shock effect of both the crack spread futures and the ETF crack spread is more persistent than the shock effect of the crude oil spot on those two crack spread derivatives. Moreover, the $\lambda_{1}+\lambda_{2}$ estimates of the DCC ECM-MGARCH 2 model are close to (but less than) 1 , meaning that a shock can move the correlation away from its long-run average for a considerable amount of time. Therefore, the DCC MGARCH model may capture the variation in the correlation between the crude oil spot and ETF crack spread markets more effectively than the CCC MGARCH model.

Figure 3 presents the conditional correlation of the CCC MGARCH models (the straight line) and the conditional correlation of the DCC MGARCH models (the time-varying line). The correlation between the oil spot and ETF crack spread markets in the CCC model (0.5990) is relatively higher than that between the oil spot and crack spread futures markets (0.1051). 
Table 5. Error correction models

\begin{tabular}{|c|c|c|c|c|c|c|c|c|}
\hline & \multicolumn{6}{|c|}{ OPEC crude oil and crack spread futures } & \multirow{2}{*}{\multicolumn{2}{|c|}{$\begin{array}{c}\text { OPEC crude oil and ETF } \\
\text { crack spread }\end{array}$}} \\
\hline & \multicolumn{2}{|c|}{$\begin{array}{c}\text { ECM } 1 \\
\text { (Whole sample) }\end{array}$} & \multicolumn{2}{|c|}{$\begin{array}{c}\text { ECM } 2 \\
(2005: 10-2009: 04)\end{array}$} & \multicolumn{2}{|c|}{$\begin{array}{c}\text { ECM } 3 \\
(2009: 05-2011: 12)\end{array}$} & & \\
\hline & $\Delta s_{t-1}$ & $\Delta c s_{t-1}$ & $\Delta s_{t-1}$ & $\Delta c s_{t-1}$ & $\Delta s_{t-1}$ & $\Delta c s_{t-1}$ & $\Delta s_{t-1}$ & $\Delta E T F_{t-1}$ \\
\hline$E C T_{t-1}$ & -0.0060 & $0.0197^{* *}$ & -0.0007 & $0.0166^{* *}$ & $-0.0141^{*}$ & $0.0759 * *$ & $-0.0233^{* *}$ & $0.0044^{*}$ \\
\hline$\Delta s_{t-1}$ & $0.2455^{* *}$ & $0.2869^{*}$ & $0.2401^{* *}$ & $0.3180^{*}$ & $0.2569^{* *}$ & 0.2742 & 0.0241 & -0.0038 \\
\hline$\Delta c s_{t-1}$ & 0.0043 & -0.0022 & -0.0031 & 0.0138 & $0.0219^{* *}$ & -0.0220 & & \\
\hline$\Delta E T F_{t-1}$ & & & & & & & $0.7450^{* *}$ & -0.0113 \\
\hline constant & 0.0003 & 0.0000 & 0.0001 & 0.0000 & 0.0089 & 0.0002 & 0.0001 & 0.0004 \\
\hline
\end{tabular}

Note: ${ }^{*}$ and ${ }^{* *}$ denote rejection of the null hypothesis that the coefficient is not significant at the $5 \%$ and $1 \%$ levels, respectively.

Table 6. Multivariate GARCH models

\begin{tabular}{|c|c|c|c|c|c|}
\hline & & \multicolumn{2}{|c|}{$\begin{array}{c}\text { ECM MGARCH } 1 \\
\text { (oil spot and crack spread futures) } \\
(2009: 05-2011: 12)\end{array}$} & \multicolumn{2}{|c|}{$\begin{array}{c}\text { ECM MGARCH } 2 \\
\text { (oil spot and ETF crack spread) } \\
(2009: 05-2011: 12)\end{array}$} \\
\hline & & $\Delta s_{t-1}$ & $\Delta c s_{t-1}$ & $\Delta s_{t-1}$ & $\Delta E T F_{t-1}$ \\
\hline \multirow[t]{4}{*}{ CCC } & $\operatorname{arch}(1)$ & $0.1759^{* *}$ & $0.0805^{* *}$ & $0.0624^{* *}$ & $0.0260^{* *}$ \\
\hline & $\operatorname{garch}(1)$ & $0.5397^{* *}$ & $0.8968^{* *}$ & $0.8915^{* *}$ & $0.9618^{* *}$ \\
\hline & constant & $0.0000^{*}$ & $0.0001^{*}$ & $0.0000^{*}$ & 0.0000 \\
\hline & $\rho$ & $0.1051^{* *}$ & & $0.5990^{* *}$ & \\
\hline \multirow[t]{5}{*}{$D C C$} & $\operatorname{arch}(1)$ & $0.1800^{* *}$ & $0.0815^{* *}$ & $0.0734^{* *}$ & $0.0312^{* *}$ \\
\hline & $\operatorname{garch}(1)$ & $0.5923^{* *}$ & $0.8952^{* *}$ & $0.8743^{* *}$ & $0.9624^{* *}$ \\
\hline & constant & $0.0000^{*}$ & $0.0001^{*}$ & $0.0000^{*}$ & 0.0000 \\
\hline & $\lambda_{1}$ & 0.0490 & & $0.0286^{*}$ & \\
\hline & & $0.7083^{* *}$ & & $0.9218^{* *}$ & \\
\hline
\end{tabular}

Note: ${ }^{*}$ and ${ }^{* *}$ denote rejection of the null hypothesis that the coefficient is not significant at the $5 \%$ and $1 \%$ levels, respectively.

In terms of the DCC model, the conditional correlation between the oil spot and crack spread futures markets is low and sometimes negative, while that between the oil spot and ETF crack spread markets is more than 0.5 most of the time. Because the dynamic correlations change strongly over time in both the ECM-MGARCH 1 and ECM-MGARCH 2 models, the DCC model is more appropriate than the CCC 


\section{Estimated conditional correlation of oil spot and crack spread futures} (ECM MGARCH 1)

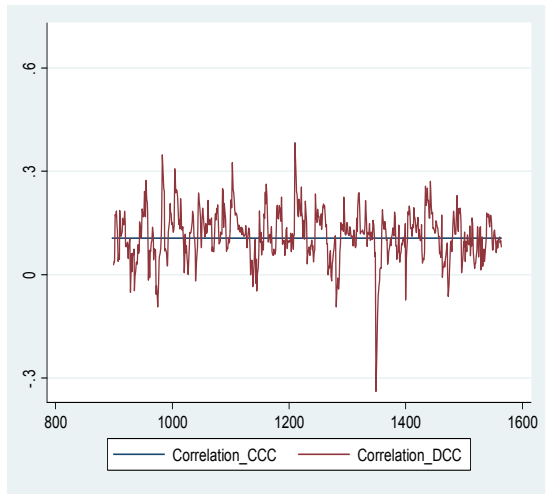

Estimated conditional correlation of oil spot and ETF crack spread (ECM MGARCH 2)

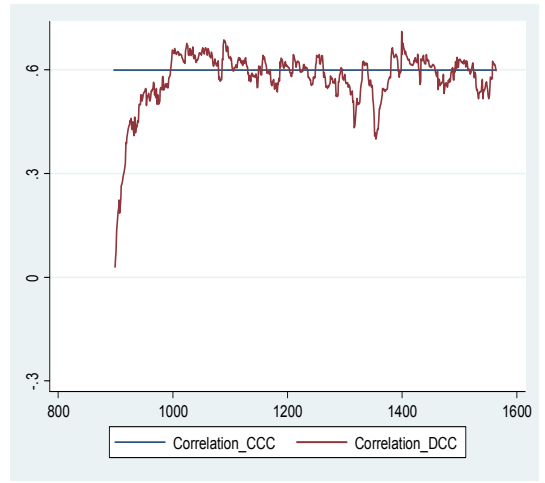

Figure 3. Comparison of unconditional correlations and estimated conditional correlations

model, which assumes constant correlation. Accordingly, only the DCC MGARCH model is used in the forecasting exercise.

\subsection{Forecasting performance}

The forecasting results are reported in Table 7. For the out-of-sample forecasts, the data are divided into two periods: the first period is from May 2009 to September 2011, and the second period is from October 2011 to December 2011. Based on the ECM and ECM MGARCH models, the forecasting performance of the crack spread futures and the crack spread ETF is evaluated. The RWM is used as a benchmark for evaluating the different forecasting models. We first discuss the forecasting results from the ECMs and then those from the ECM MGARCH models.

Based on the MAE $(I)$ and RMSE $(I)$, the ECMs for crack spread futures and the ETF crack spread outperform the RWM both in-sample and out-of-sample. This result is consistent with that of Murat and Tokat (2009), who show that the ECM for crack spread futures outperforms the RWM in predicting WTI crude oil price movements. Moreover, we find that the ETF crack spread is a better predictor of OPEC crude oil price movements than the crack spread futures both in-sample and out-of-sample. The result of the DM test indicates that these results are significant at the 5\% level.

Based on the MAE (II) and RMSE (II), the ECMMGARCH model for the ETF crack spread shows better in-sample forecasting performance than the model for crack spread futures and the RWM. However, for out-of-sample, it is difficult to derive consistent results between the two instruments. The MAE (II) suggests that the ETF crack spread is a better predictor than the crack spread futures, whereas the RMSE (II) suggests otherwise. Nevertheless, both ECM-MGARCH models outperform the RWM both in-sample and out-ofsample. Overall, the forecasting performance of both the ECM and ECM-MGARCH models confirms that information in both the crack spread futures and the ETF crack spread markets can be used to predict oil price movements. In addition, on average, the ETF crack spread seems to be a better predictor than the 
Table 7. Forecasting performance

\begin{tabular}{lccccccc}
\hline & & \multicolumn{3}{c}{ In-sample } & \multicolumn{3}{c}{ Out-of-sample } \\
\cline { 3 - 8 } & & cs & ETF & RWM & cs & ETF & RWM \\
\hline ECM & MAE(I) & 0.011023 & 0.009897 & 0.011183 & 0.008965 & 0.007734 & 0.009264 \\
& RMSE(I) & 0.014365 & 0.012767 & 0.014525 & 0.010914 & 0.009943 & 0.011206 \\
& & & & & & & \\
ECM MGARCH & MAE(II) & 0.781295 & 0.762333 & 0.769217 & 0.684738 & 0.649659 & 0.820236 \\
& RMSE(II) & 0.999029 & 0.980128 & 0.999177 & 0.836930 & 0.846540 & 0.992240 \\
\hline
\end{tabular}

Note: The $M A E(I I)$ and RMSE (II) of the RWM are derived by dividing the residual by the time-invariant variance.

crack spread futures. This result is as expected given that the correlation between the oil spot and ETF crack spread markets is relatively higher than that between the oil spot and crack spread futures markets (see Figure 3). A possible explanation for this result may be the institutional differences (such as the magnitude of transaction costs and trading systems) between the futures and ETF markets. Specifically, given that the ETF trading system is accessible to anyone, the ETF market attracts a greater variety of investors (not only oil refiners) and is thus more likely to incorporate new information regarding crude oil spot prices faster than the futures markets, in which most transactions are completed by refinery companies or institutional investors.

\section{Conclusion}

A number of studies have investigated the dynamics of crude oil spot prices. However, there is lack of research on modeling and forecasting the movements of OPEC Reference Basket (ORB) prices. Accordingly, this study focuses on the dynamics of the OPEC crude oil prices. In response to the emerging consensus that crude oil and refined product (as well as crack spread) prices are cointegrated, we examine the usefulness of the two crack spread derivatives products (namely, crack spread futures and the ETF crack spread) for modeling and forecasting the daily OPEC crude oil spot prices. Specifically, using the Error Correction Model (ECM) and the Multivariate GARCH (MGARCH) model, we explore the long-run relationship between the OPEC crude oil spot market and the two crack spread derivatives markets: the crack spread futures and ETF crack spread markets. We also evaluate the forecasting performance of the two crack spread derivatives with that of the conventional Random Walk Model (RWM).

Based on the two detected structural breaks, we apply a Granger-causality test for the OPEC crude oil spot market and the crack spread futures market on the entire sample period and the three sub-sample periods: the pre-crisis, crisis, and post-crisis periods. A change in the lead-lag relationship between the oil spot and crack spread futures markets is observed over the sub-sample periods. In particular, a unidirectional relationship from the crude oil spot market to crack spread futures is detected for the pre-crisis and crisis periods; however, the relationship between the two markets is reversed in the post-crisis period. The change in this causal relationship may be explained by the increasing need of the oil-related financial market for oil price hedging and investments. Regarding the relationship between the crude oil spot and ETF crack spread markets, the Granger-causality test indicates a strong unidirectional relationship from the ETF crack spread market to the OPEC crude oil market. The results therefore suggest that, in the post-crisis period, both crack spread derivatives may be good predictors of OPEC oil price movements.

In terms of the forecasting performance, we find that the forecasting models (the ECM and ECMMGARCH models) based on crack spread futures and the ETF crack spread outperform the RWM both insample and out-of-sample. Thus, the results confirm that there is valuable information in both the crack spread futures and the ETF crack spread markets. In 
addition, on average, the ETF crack spread is a better predictor of OPEC crude oil price movements than the crack spread futures both in-sample and out-ofsample. This result suggests that the ETF crack spread market contributes more to the forecasting models than the crack spread futures market.

Our findings provide the following practical implications for policymakers and investors. First, the results suggest that shocks in refined product futures and ETF markets could easily spread to the crude oil spot market, which could impact oil production decisions. Policymakers should therefore design policies to prevent extreme fluctuations in the prices of derivative products caused by speculators. Second, our results suggest that investors could (partly) predict crude oil spot price movements using information flows from the crack spread futures and ETF crack spread markets. In addition, the ETF crack spread price is a better predictor in that the ETF market incorporates new information regarding crude oil spot prices faster than the futures market. Hence, our findings are useful for institutional and individual investors who are interested in understanding and forecasting OPEC crude oil dynamics.

However, our results are not without limitations. First, in comparing the forecasting performance of crack spread futures and the ETF crack spread, only the post-crisis data (the data from May 2009 to December 2011) are used. However, the data used in the forecasting models correspond to the launch of oil and refined product ETFs in approximately 2008 and the change in the lead-lag relationship between crude oil and crack spread futures prices in April 2009. Further study using longer periods of ETF data would be helpful in understanding the relationship between the crude oil spot and crack spread ETF markets. Second, only the 2:1:1 crack spread is evaluated in this study. Other multi-product crack spread variants may also be useful in explaining oil price movements. Finally, our analysis only focuses on forecasting OPEC crude oil prices. The approach can be easily adapted to forecasting other benchmarks of crude oil prices, including WTI (which is considered by Murat and Tokat (2009)), Brent and Dubai. Further research on this subject could lead to improved price forecasts and risk management in oil and refined product markets.

\section{References}

Asche, F., Gjolberg, O., \& Völker, T. (2003). Price relationships in the petroleum market: an analysis of crude oil and refined product prices. Energy Economics, 25 (3), 289-301.

Bollerslev, T., Engle, R. F., \& Wooldridge, J. M. (1988). A capital asset pricing model with time-varying covariances. Journal of Political Economy, 96 (1), 116-131.

Chinn, M. D., \& Coibion, O. (2014). The predictive content of commodity futures. Journal of Futures Markets, 34 (7), 607-636.

Diebold, F. X., \& Mariano, R. S. (1995). Comparing predictive accuracy. Journal of Business and Economic Statistics, 13 (3), 253-265.

Edwards, F. R, \& Ma, C. (1992). Futures and options. New York, NY: McGraw-Hill.

Engle, R. F. (2002). Dynamic conditional correlation: A Simple Class of Multivariate Generalized Autoregressive Conditional Heteroskedasticity Models. Journal of Business and Economic Statistics, 20 (3), 339-350.

Engle, R. F., \& Granger, C. W. J. (1987). Co-integration and error correction: representation, estimation, and testing. Econometrica, 55 (2), 251-276.

Gjolberg, O., \& Johnsen, T. (1999). Risk management in the oil industry: can information on long-run equilibrium prices be utilized? Energy Economics, 21 (6), 517-527.

Haigh, M. S., \& Holt, M. T. (2002). Crack spread hedging: accounting for time-varying volatility spillovers in the energy futures market. Journal of Applied Econometrics, 17 (3), 269-289.

Heinkel, R., Howe, M., \& Hughes, J. S. (1990). Commodity convenience yields as an option profit. Journal of Futures Markets, 10 (5), 519-533.

Johansen, S. (1988). Statistical analysis of cointegration vectors. Journal of Economic Dynamics and Control, 12 (2-3), 231-234.

Johansen, S. (1991). Estimation and hypothesis testing of cointegration vectors in Gaussian Vector Autoregressive Models. Econometrica, 59 (6), 1551 1580 .

Kaldor, N. (1939). Speculation and economic stability. Review of Economic Studies, 7 (1), 1-27.

Kocagil, A. E. (2004). Optionality and daily dynamics of convenience yield behavior: an empirical 
analysis. The Journal of Financial Research, 27 (1), 143-158.

Kroner, K. F., \& Sultan, J. (1993). Time-varying distributions and dynamic hedging with foreign currency futures. Journal of Financial and Quantitative Analysis, 28 (4), 535-551.

Lanza, A., Manera, M., \& Giovannini, M. (2005). Modeling and forecasting co-integrated relationships among heavy oil and product prices. Energy Economics, 27 (6), 831-848.

Lean, H. H., McAleer, M., \& Wong, W. K. (2010). Market efficiency of oil spot and futures: a mean-variance and stochastic dominance approach. Energy Economics, 32 (5), 979-986.

Ma, C. (1989). Forecasting efficiency of energy futures prices. Journal of Futures Markets, 9 (5), 393-419.

Murat, A., \& Tokat, E. (2009). Forecasting oil price movements with crack spread futures. Energy Economics, 31 (1), 85-90.

Serletis, A. (1994). A co-integration analysis of petroleum futures prices. Energy Economics, 16 (2), 93-97.

U.S. Energy Information Administration. (2014, May 6). What drives crude oil prices? Retrieved from http://www.eia.gov/finance/markets/supply-opec. cfm

Verleger, P. K. (1982). The determinants of official OPEC crude oil prices. Review of Economics and Statistics, 64 (2), 177-183.

Verleger, P. K. (2011). The margin, currency, and the price of oil. Business Economics, 46 (2), 71-82.

Zivot, E., \& Andrews, D. W. K. (1992). Further evidence on the great crash, the oil-price shock, and the unit-root hypothesis. Journal of Business and Economic Statistics, 10 (3), 251-270.

\section{Acknowledgements}

We sincerely thank two anonymous referees for constructive comments and suggestions that improved the contributions and presentation of the paper. 
